Purdue University Purdue e-Pubs

6-14-2017

\title{
A Desktop Procedure for Measuring the Transmission Loss of Automotive Door Seals
}

Weimin Thor

Purdue University, wthor@purdue.edu

J Stuart Bolton

Purdue University, bolton@purdue.edu

Follow this and additional works at: http://docs.lib.purdue.edu/herrick

Thor, Weimin and Bolton, J Stuart, "A Desktop Procedure for Measuring the Transmission Loss of Automotive Door Seals" (2017).

Publications of the Ray W. Herrick Laboratories. Paper 154.

http://docs.lib.purdue.edu/herrick/154

This document has been made available through Purdue e-Pubs, a service of the Purdue University Libraries. Please contact epubs@purdue.edu for additional information. 


\section{A DESKTOP PROCEDURE FOR MEASURING THE TRANSMISSION LOSS OF AUTOMOTIVE DOOR SEALS}

Weimin Thor, J. Stuart Bolton, Ray W. Herrick Laboratories, Purdue University 


\section{Introduction}

\section{Increasing concern with acoustic environment within a vehicle}

- Previous methods to measure acoustic properties require large scale facilities which are expensive.

- Objective here is to develop a simpler and more economical desktop procedure to allow easy and fast acoustic measurement of automotive door seals.

- Procedure described here mainly adapted from four-mic measurement method (E2611 ASTM International, 2009).

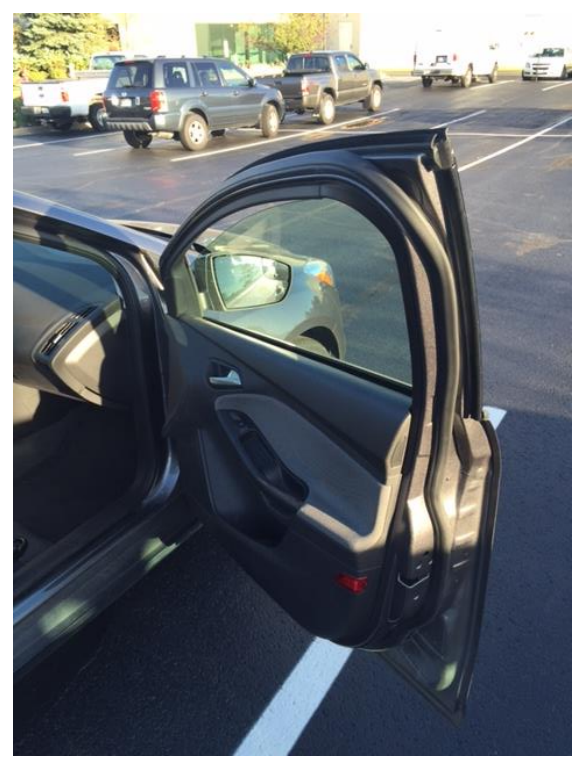




\section{Seal Descriptions}

- Come in many forms

\begin{tabular}{|c|c|c|}
\hline \multicolumn{3}{|c|}{ Primary Bulb Seals } \\
\hline Seals & Characteristics & Clamp method \\
\hline & & $\begin{array}{l}\text { Designed } \\
\text { to have } \\
\text { only one } \\
\text { air cavity } \\
\text { No vent } \\
\text { holes }\end{array}$ \\
\hline
\end{tabular}

\begin{tabular}{|c|c|c|}
\hline \multicolumn{3}{|c|}{ Multiple Chamber Seals } \\
\hline Seals & Characteristics & Clamp method \\
\hline & & $\begin{array}{l}\text { Designed } \\
\text { to have } \\
\text { two or } \\
\text { more air } \\
\text { cavities } \\
\text { No vent } \\
\text { holes }\end{array}$ \\
\hline
\end{tabular}




\section{Previous Work}

\section{Robert J. Danforth III and Luc Mongeau, "Sound transmission}

through road vehicle primary bulb seal assemblies," HL 96-14

\section{Report \#3086-2, December 1996}

- Experiments using a small quiet wind tunnel, bulb seals excited by aerodynamic pressure.

- Sound pressure transmitted into enclosure measured for varying flow velocities, cavity dimensions, and other parameters.

- Noise reduction measurements performed using reverberation room - effect of compression.
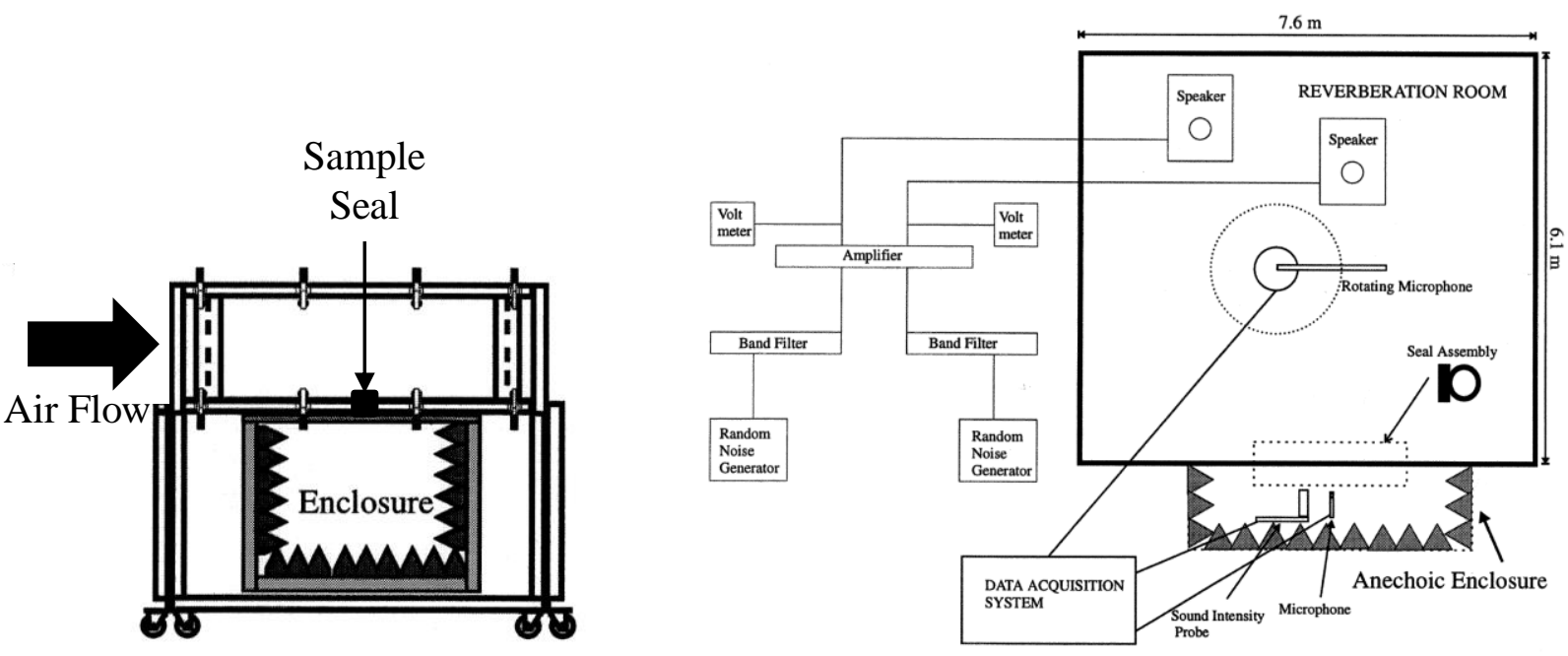


\section{Previous Work}

Junhong Park and Luc Mongeau, "Effects of mechanical properties of sealing systems on aerodynamic noise generation inside vehicles," HL 2002-1 May 2002

- Numerical analysis of sound transmission through a bulb seal was done using the finite element method.

- This allows the complex geometry of a bulb seal as well as its boundary conditions to be taken into consideration.

- Effects of seal mechanical properties on interior aerodynamic noise were investigated. Seals made of EPDM and TPE were experimented using the reverberation room test method.
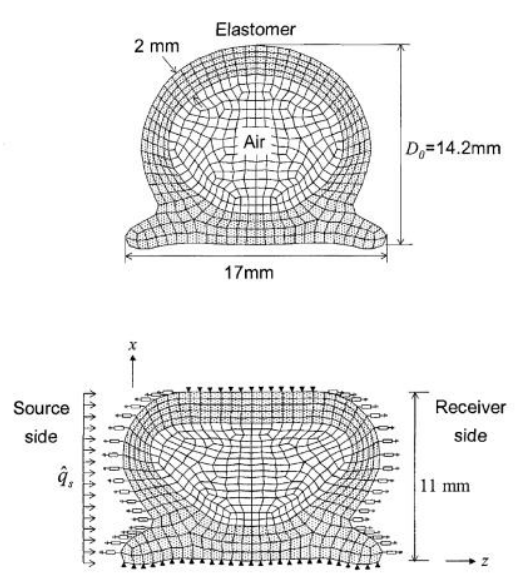


\section{Previous Work}

Julio A. Cordioli et al., "Application of the Hybrid FE-SEA Method to Predict Sound Transmission Through Complex Sealing Systems," SAE International 2011-01-1708, May 2011

- Presented a numerical validation of Hybrid FE-SEA model

- Door components mounted in reverberation room aperture

- Transmitted sound level measured with and without seal in place.

- Typical STL about $30 \mathrm{~dB}$.
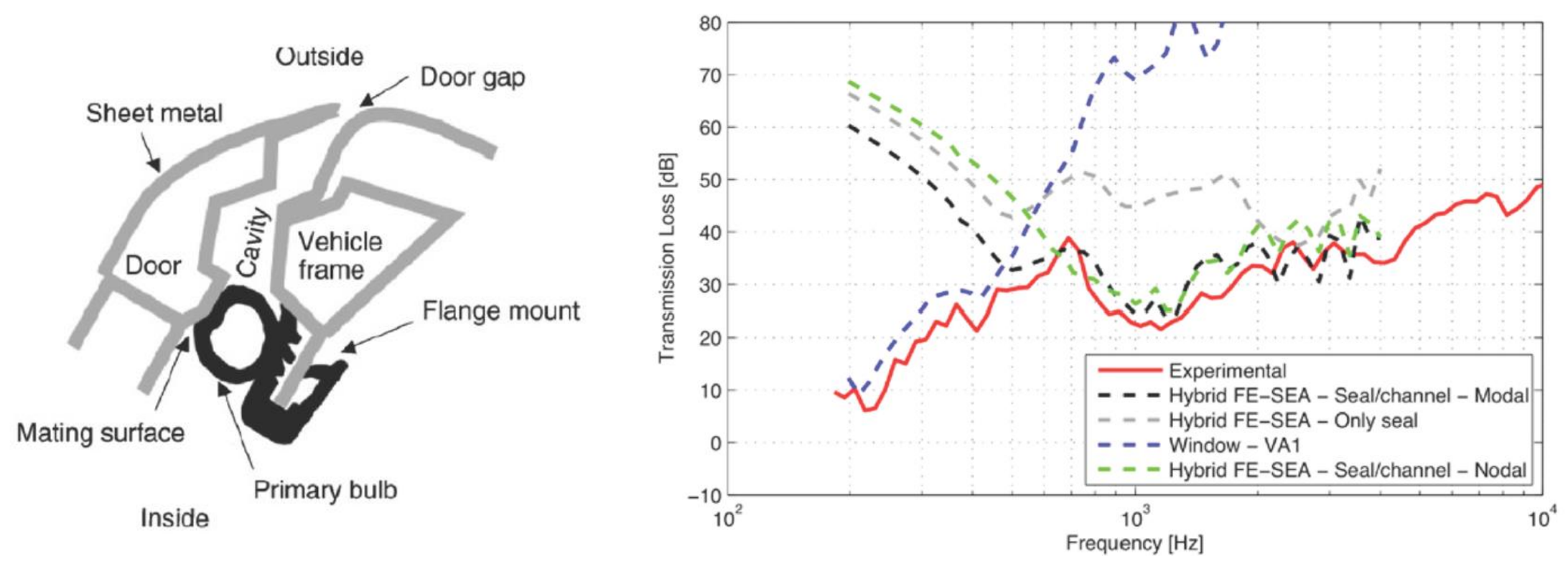


\section{Contents}

Goal: To create a desktop procedure as a simple alternative to previous measurement methods

- Measurement Procedure and Apparatus

- Correction Procedure - to compensate for effects of clamp

- Seals Tested

- Transmission Loss and Effect of Compression 


\section{4-Mic Procedure (E2611 ASTM International, 2009)}

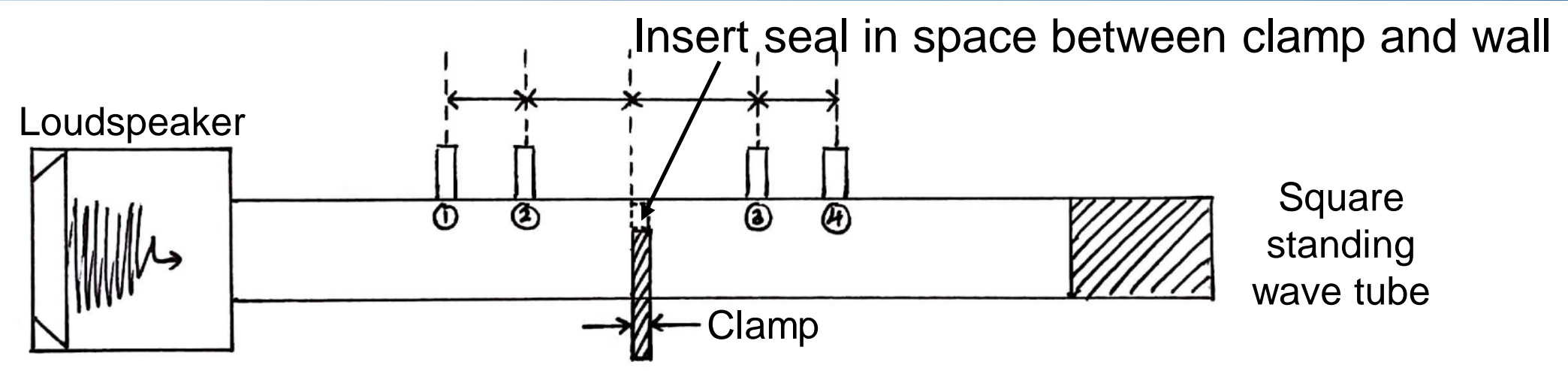

- Estimate transfer matrix elements:

- Transmission Coefficient

$$
T_{a}=\frac{2 e^{j k d}}{T_{11}+\frac{T_{12}}{\rho_{0} c}+\rho_{0} c T_{21}+T_{22}}
$$

- Transmission Loss

$$
T L=20 \log _{10} \frac{1}{\left|T_{a}\right|}
$$

- Measure combined transmission loss of seal and clamp by using two load method 


\section{Experimental Apparatus}

\section{Apparatus used in the experiment}

- Automotive door seals cut to the width of the standing wave tube $(6.35 \mathrm{~cm})$

- $6.35 \mathrm{~cm} \times 6.35 \mathrm{~cm}$ square standing wave tube

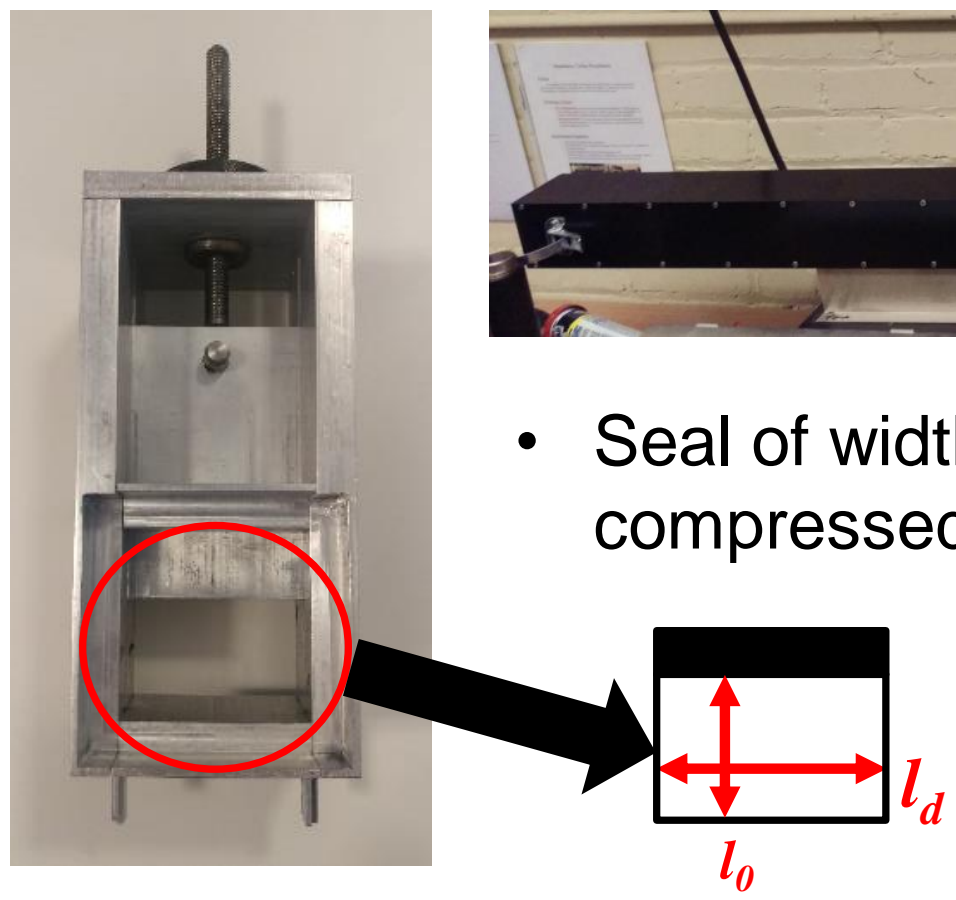

- Upper frequency limit of $2700 \mathrm{~Hz}$ due to tube dimensions - smaller tube could be used to increase upper frequency limit. 


\section{Correction Factor Calculation}

As the seal only takes up part of the standing wave tube, the measured transmission loss includes the contribution of the metal clamp (assumed to have infinite TL).

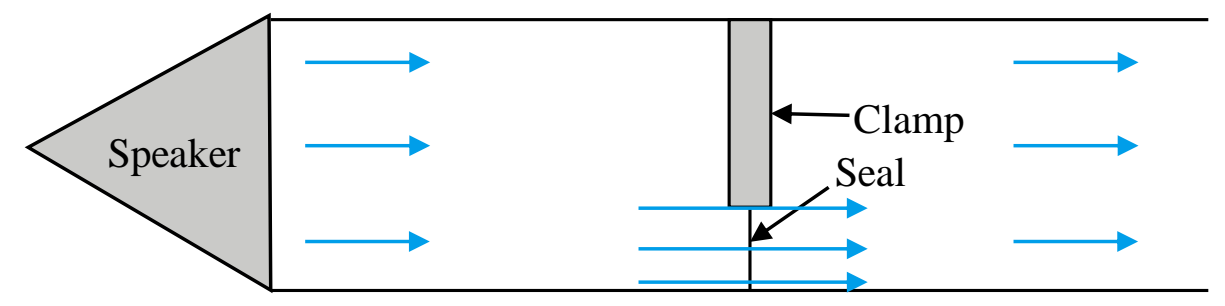

- Transmission loss measured is a combination of the seal and clamp, but the desired results is the transmission loss of the seal itself.

- A correction factor is needed to account for the area change and inertial-nearfield effects.

- Determine latter factor experimentally by measuring transmission loss of materials having known properties. 


\section{Correction Factor Calculation}

\section{Correction procedure:}

- A separate series of experiments were conducted using three "reference" materials: a lightweight, fibrous material, a polyurethane foam, and air filling the space between the clamp and the tube wall.

- Samples were cut into pieces ranging from $1.00 \mathrm{~cm}$ to $6.35 \mathrm{~cm}$ in width with an increment of $0.50 \mathrm{~cm}$.

- Similar procedure for the main experiment was then used with the individual samples.

- Measured transmission loss of full width $(6.35 \mathrm{~cm})$ sample, then represents "known" transmission loss of material.

- Find correction factor necessary to cause small

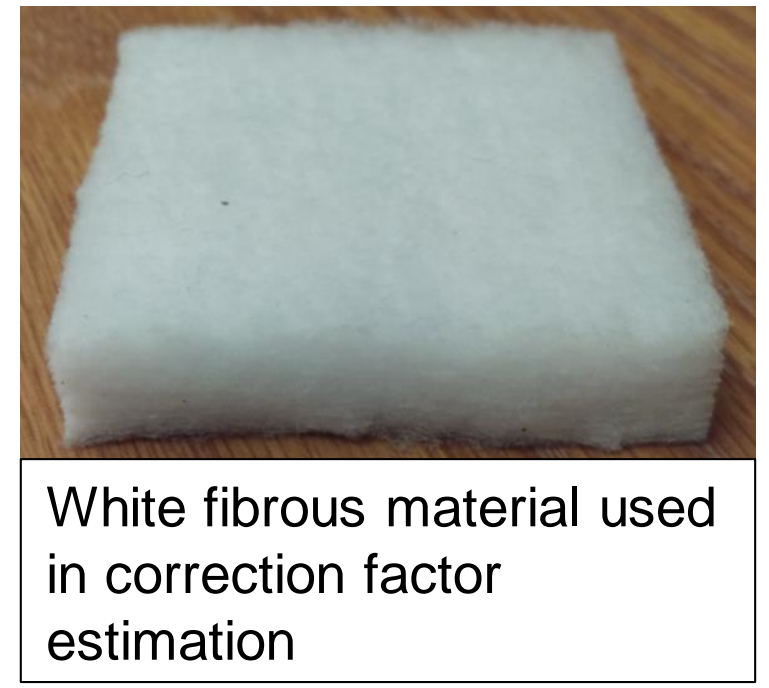
sample results to agree with full width results. 


\section{Area Correction Factor Calculation}

\section{Area correction:}

- The transmission coefficient is first adjusted to compensate for the area change

$$
T_{\text {new }}=T_{\text {original }} \times \frac{l_{d}}{l_{0}}
$$

where $T_{\text {original }}$ is the transmission coefficient of the combined system, $l_{d}$ is the width of the sample and $l_{0}$ being the width of the duct.

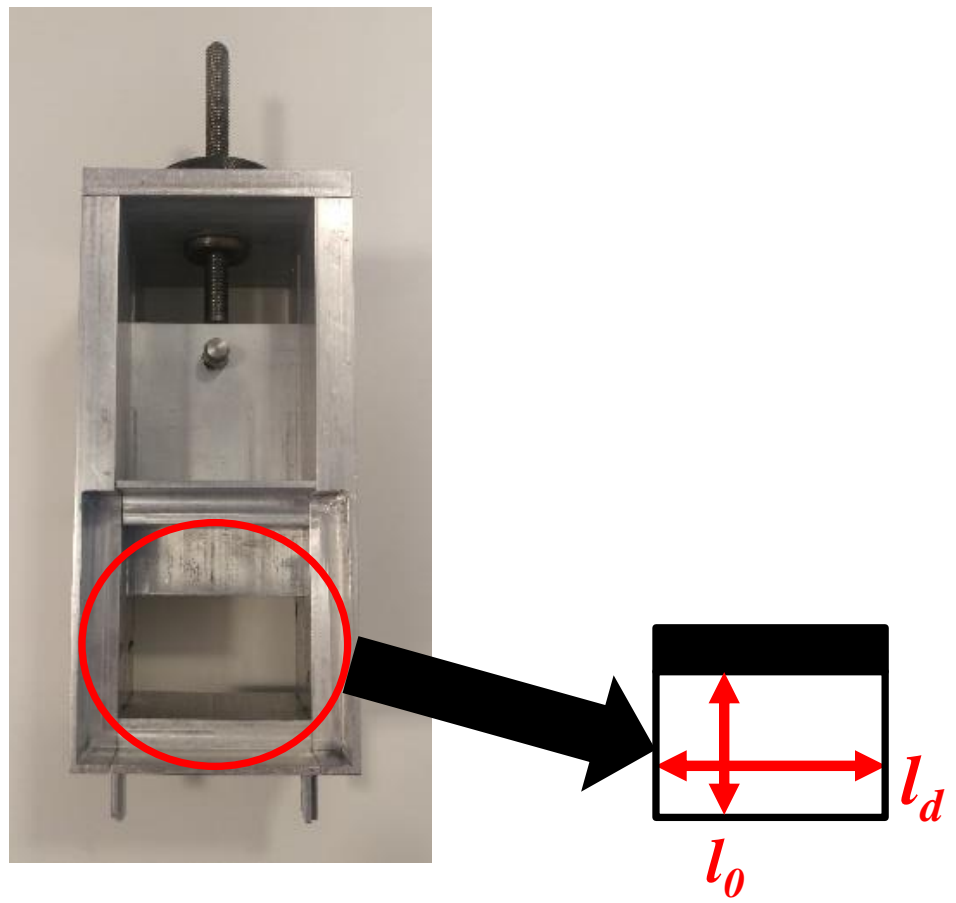




\section{Inertial-Nearfield Correction Factor Calculation}

- After obtaining the area-adjusted transmission coefficient, the inertialcorrection factor at all different frequencies can be calculated via the following formula:

$$
\alpha\left(\frac{l_{0}}{l_{d}}, \omega\right)=\frac{T_{\text {new }, \text { duct }}}{T_{\text {new }}}
$$

where $T_{\text {new,duct }}$ is the known transmission coefficient of the full width sample.

- The correction factors for three different material cases were averaged to give a single $\alpha\left(\frac{l_{0}}{l_{d}}, \omega\right)$.

- At each frequency, a polynomial was fitted to the result to obtain the following formula for the inertial-correction factor:

$$
\alpha\left(\frac{l_{0}}{l_{d}}, \omega\right)=a_{1}\left(\frac{l_{0}}{l_{d}}\right)^{2}+a_{2}\left(\frac{l_{0}}{l_{d}}\right)+a_{3}
$$




\section{Measured Inertial-Nearfield Correction Factor}

Correction factor for the white fibrous material

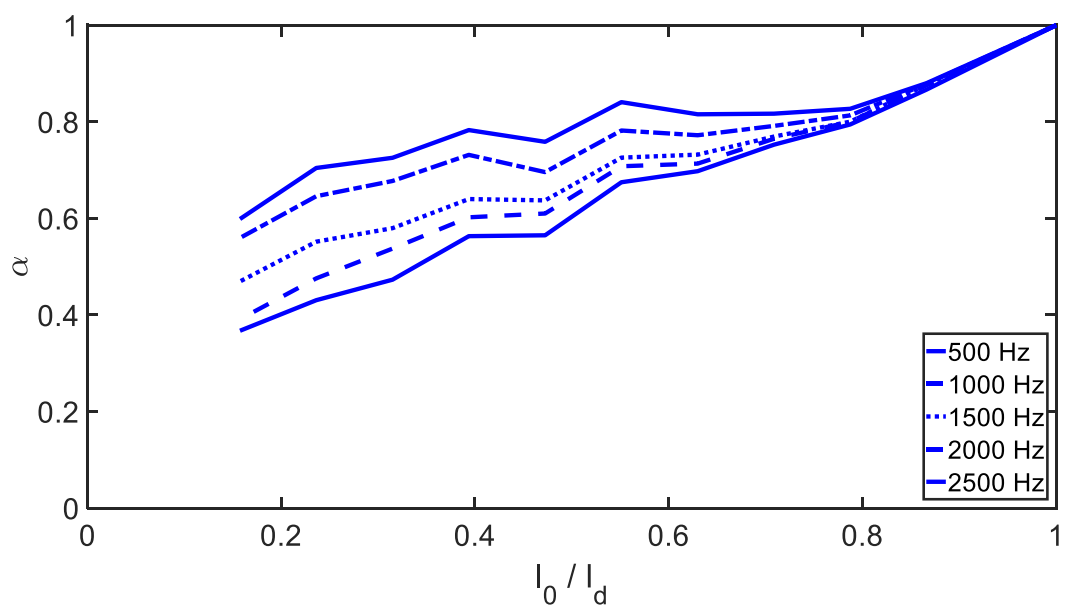

Correction factor for the layer of air

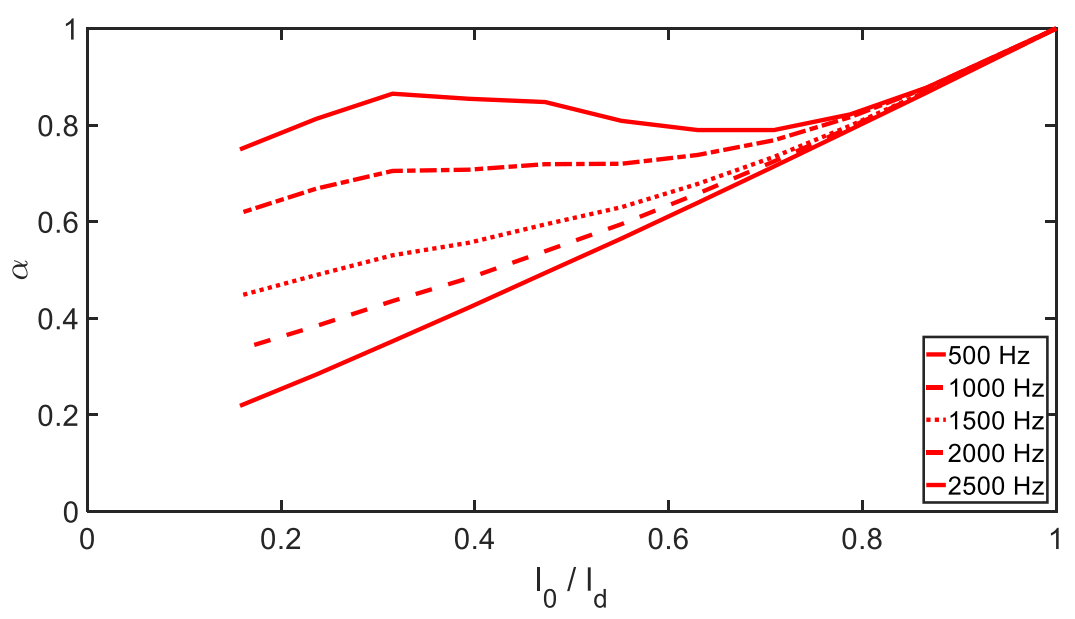

Correction factor for the green foam material

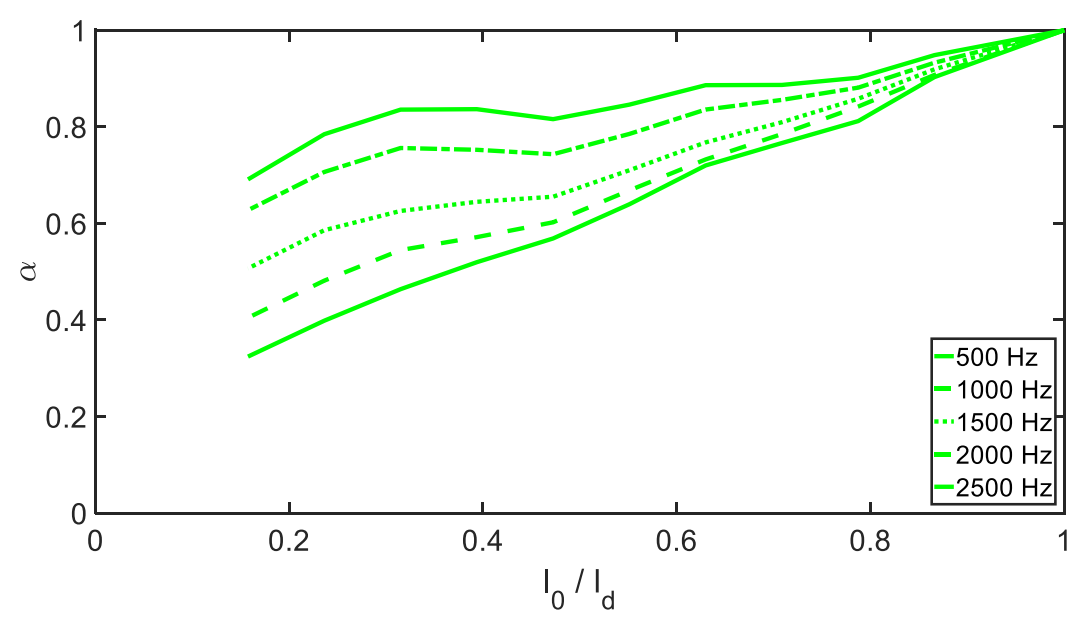

- Inertial nearfield is larger at low frequencies and for small openings as expected

- Correction factor goes to unity as sample size approaches full duct width 


\section{Inertial-Nearfield Correction Factor}

\section{Average correction factor with polynomial fit: five examples}

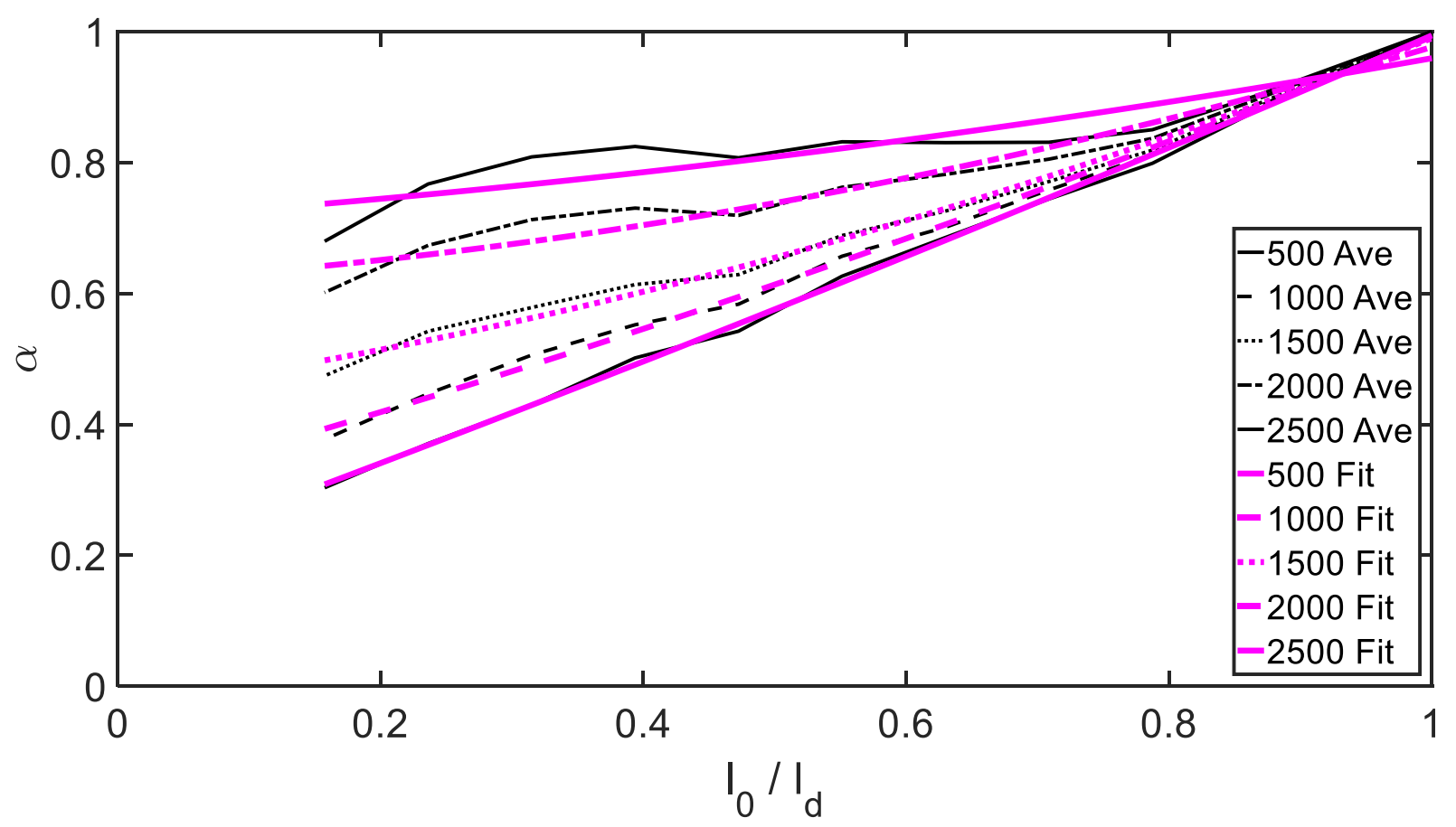

- Correction is most significant for small values of $\left(l_{0} / l_{d}\right)$ (i.e., large contraction) and low frequencies.

- Under those conditions, inertial-nearfield effect is important. 


\section{Correction Factor Implementation (Verifications)}

White fibrous material $(3.0 \mathrm{~cm})$

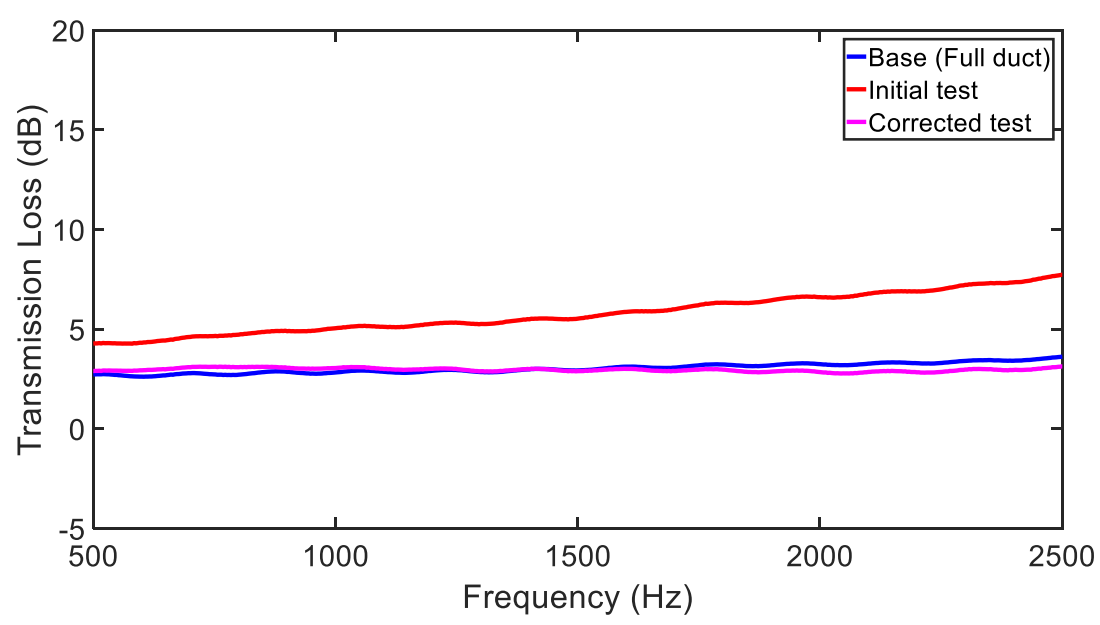

Layer of air $(3.0 \mathrm{~cm})$

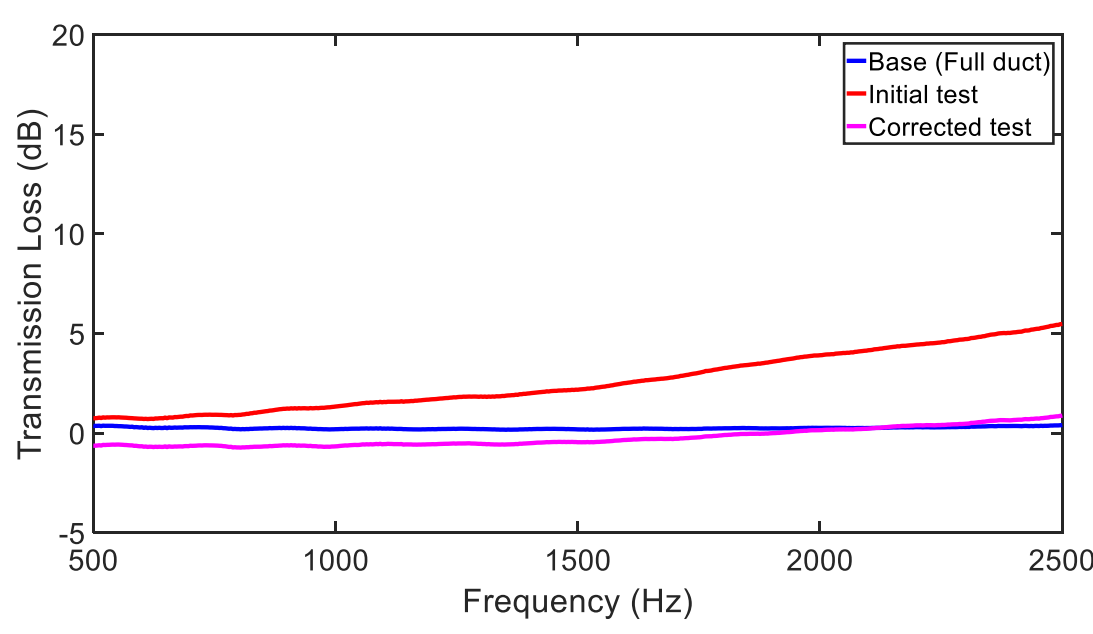

Green foam material $(3.0 \mathrm{~cm})$
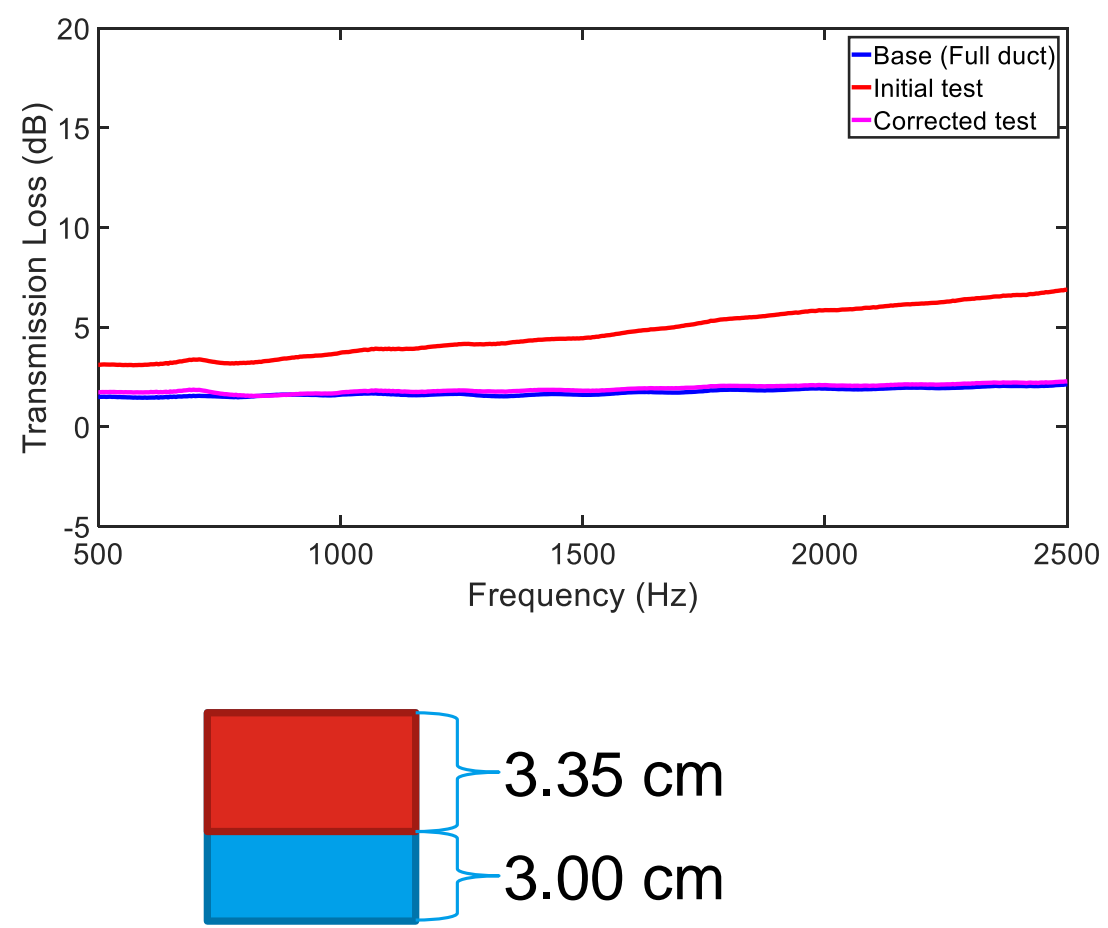

- Measured transmission losses successfully "corrected" to known "true values" 


\section{Correction Factor Implementation (Verifications)}

White fibrous material $(2.0 \mathrm{~cm})$

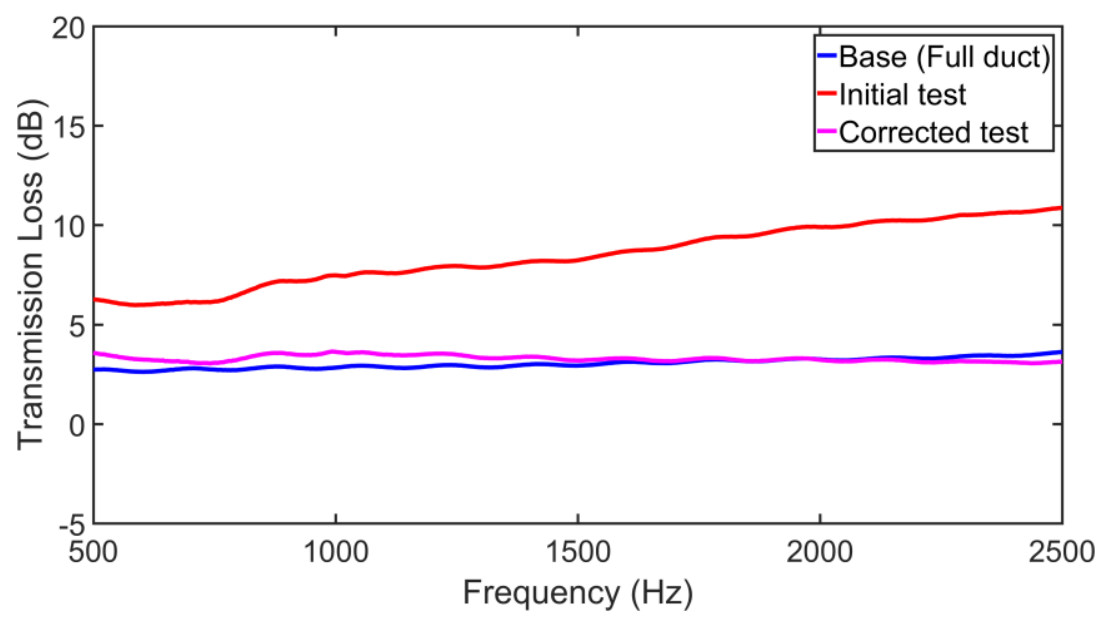

Layer of air $(2.0 \mathrm{~cm})$

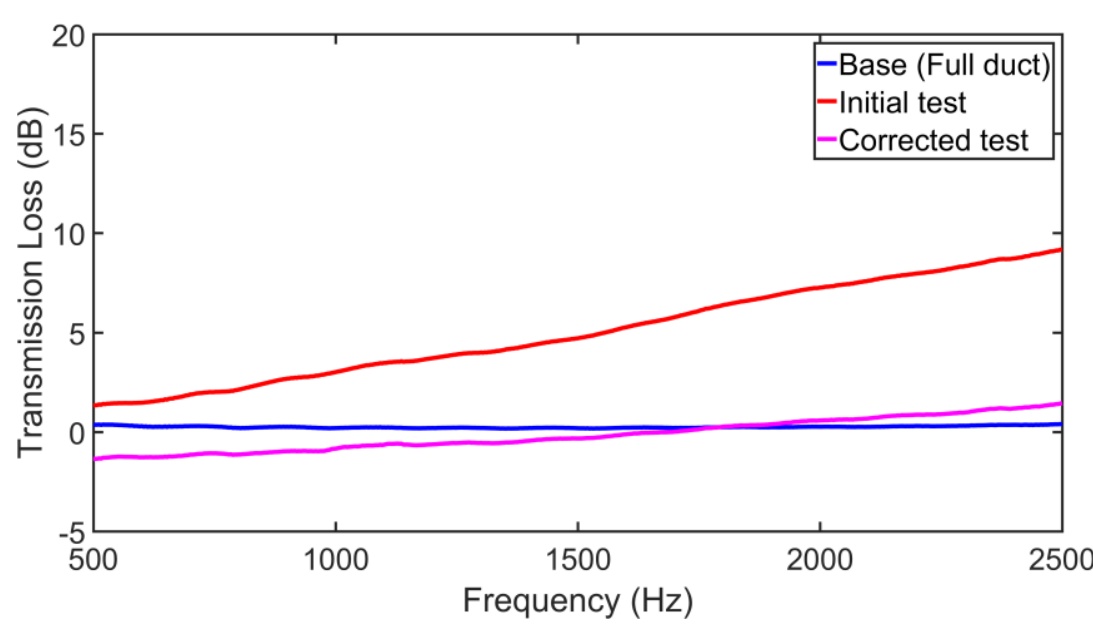

Green foam material $(2.0 \mathrm{~cm})$
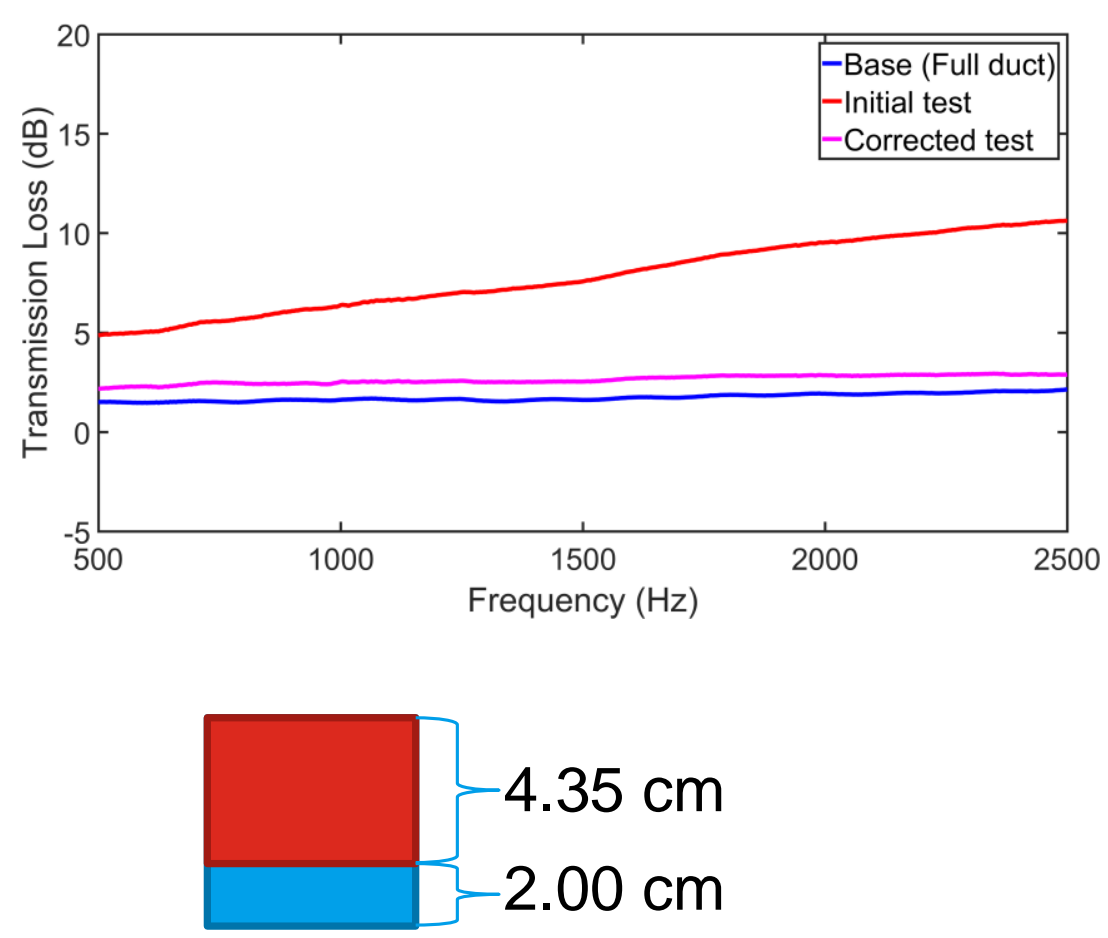

- Measured transmission losses successfully "corrected" to known "true" values 


\section{Door Seal Data Processing}

\section{After clamping the seals, experimental procedure was as follows:}

- White noise ranging from $0 \mathrm{~Hz}$ to $2700 \mathrm{~Hz}$ was generated with sound pressure measured at the respective standing wave tube locations with Bruel and Kjær microphones.

- Measurements made with two terminations.

- Samples were tested ten times at each compression level.

- Data collected was processed through MATLAB where the transmission coefficient of the different seals were calculated using the two correction factors obtained from before:

$$
\begin{aligned}
& T_{\text {seal,new }}=T_{\text {original }} \times \frac{l_{d}}{l_{0}} \quad \text { (Area correction) } \\
& T_{\text {seal }}=\alpha\left(\frac{l_{0}}{l_{d}}, \omega\right) \times T_{\text {seal,new }} \quad \text { (Inertial Nearfield correction) } \\
& T L_{\text {seal }}=20 \log _{10} \frac{1}{\left|T_{\text {seal }}\right|}
\end{aligned}
$$




\section{Type of Seals Tested}

Five different seals were tested in the development of this procedure, at varying degrees of compression.

\begin{tabular}{|c|c|c|c|c|c|}
\hline Seals & Seal only & Clamped & Seals & Seal only & Clamped \\
\hline $\begin{array}{c}\mathrm{A} \\
(1.7-0.8 \mathrm{~cm}) \\
\text { (Primary) }\end{array}$ & & & $\begin{array}{c}D \\
(1.2-0.8 \mathrm{~cm}) \\
\text { (Primary) }\end{array}$ & & 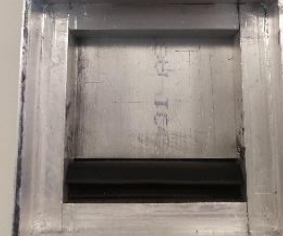 \\
\hline $\begin{array}{c}\mathrm{B} \\
(2.4-1.5 \mathrm{~cm}) \\
\text { (Primary) }\end{array}$ & & & & & \\
\hline $\begin{array}{c}\mathrm{C} \\
(3.6-2.7 \mathrm{~cm}) \\
\text { (Multi } \\
\text { chamber) }\end{array}$ & & & $\begin{array}{c}\text { (Multi } \\
\text { chamber) }\end{array}$ & & \\
\hline
\end{tabular}




\section{Corrected average transmission loss for seal A with standard}

deviations from 10 trials at each compression

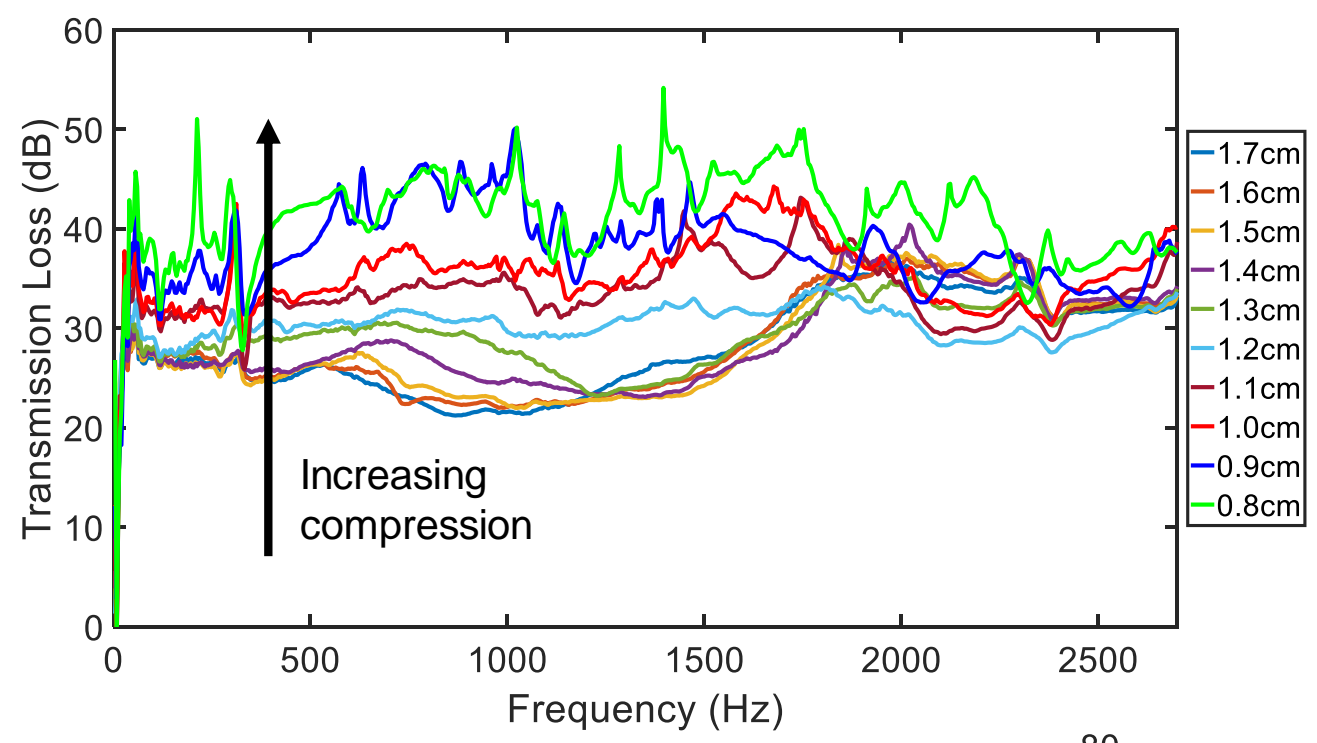

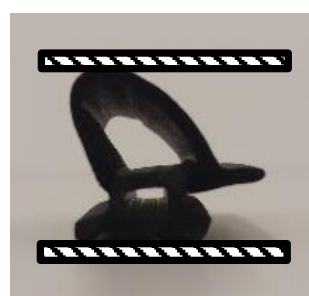

Seal A

- Essentially monotonic increase of TL with compression

- Scatter increases as compression increases

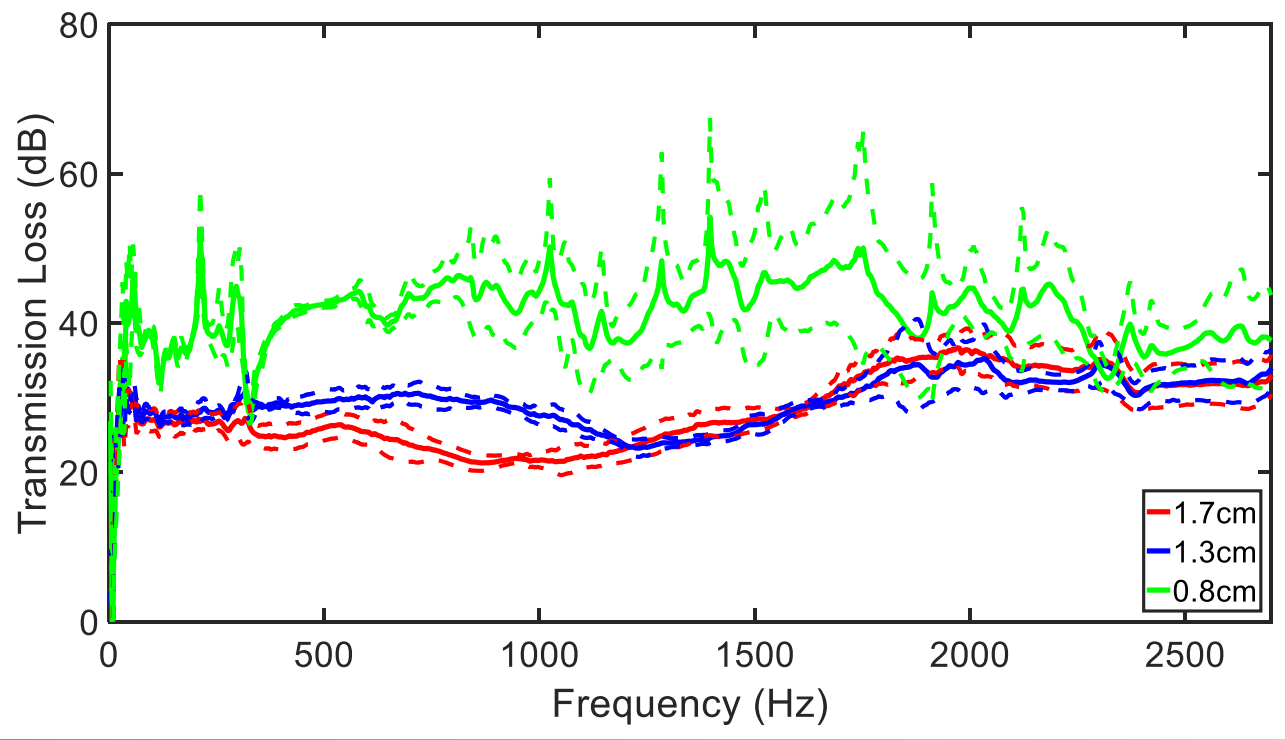




\section{Corrected average transmission loss for seal B with standard deviations from 10 trials at each compression}

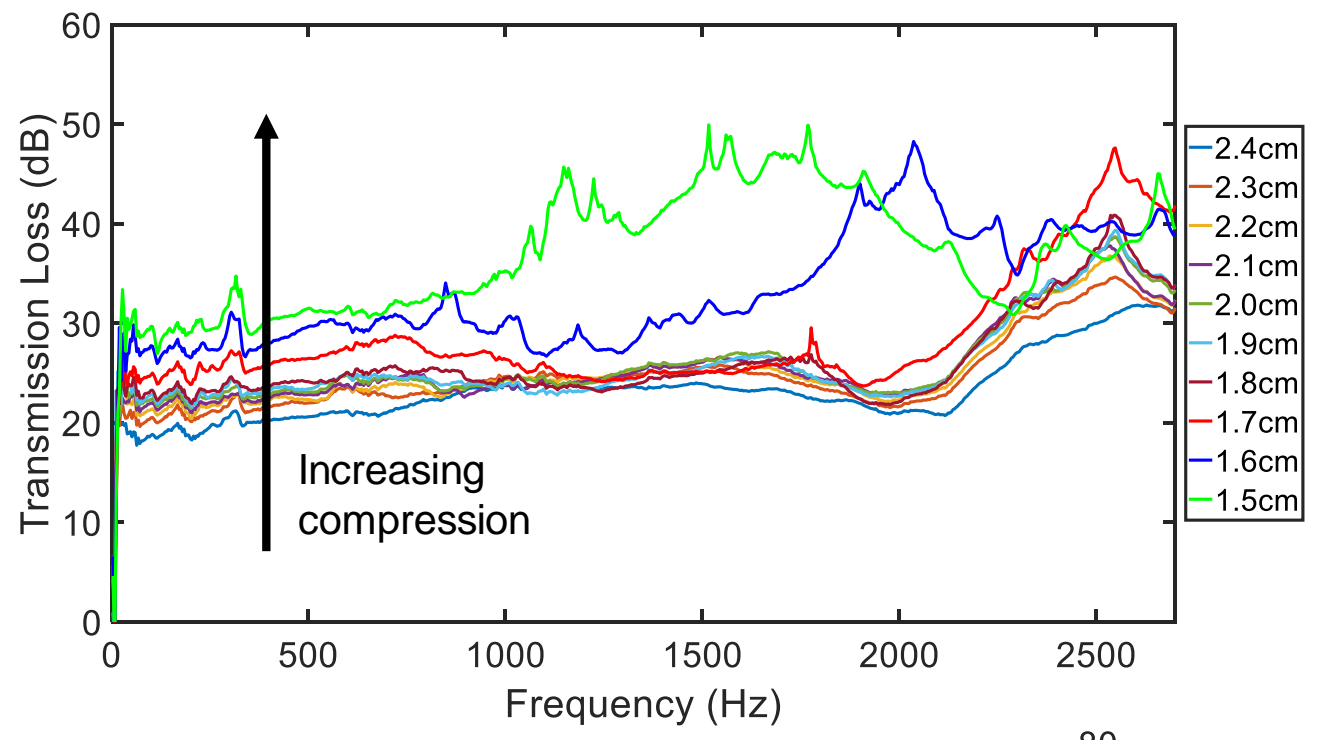

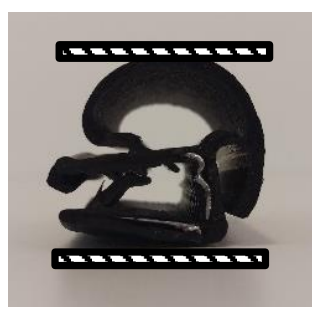

Seal B

- Note apparent shift of TL peak to lower frequencies as compression increases

- TL is similar at low compression with sudden increase at high compression

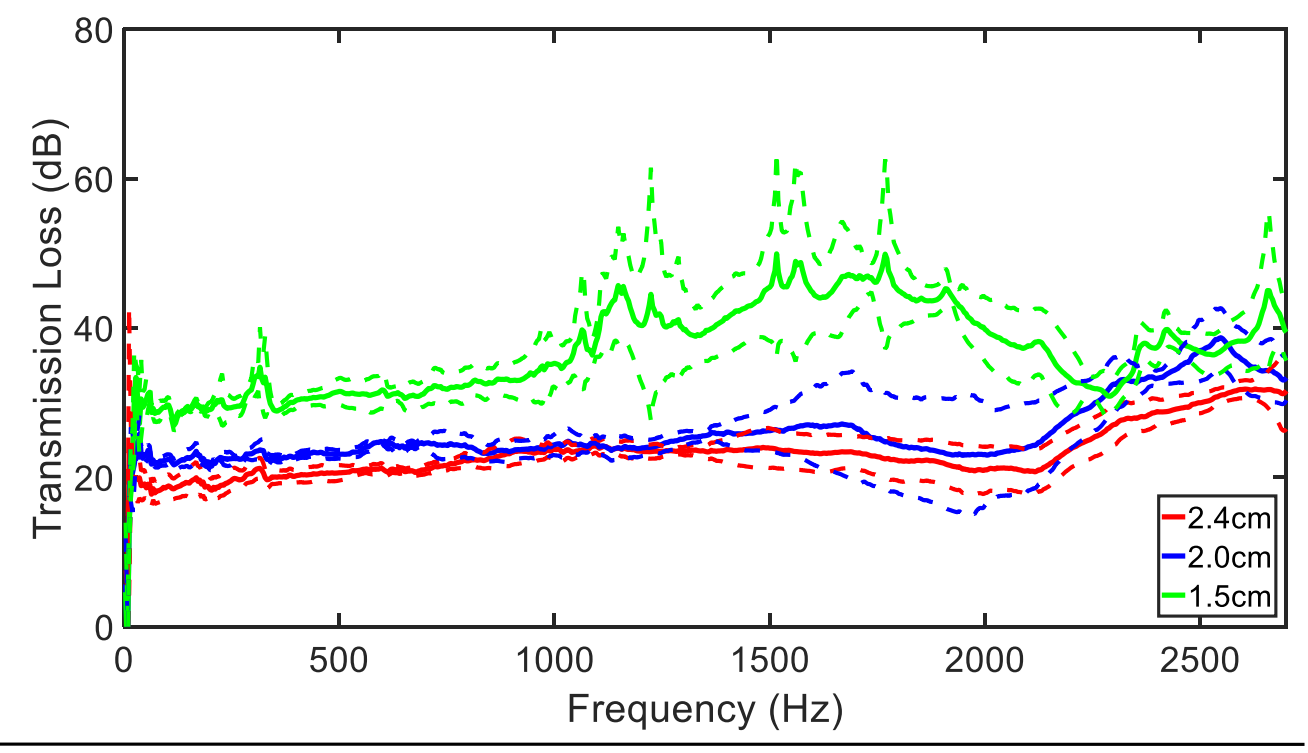




\section{Corrected average transmission loss for seal $\mathbf{C}$ with standard}

deviations from 10 trials at each compression
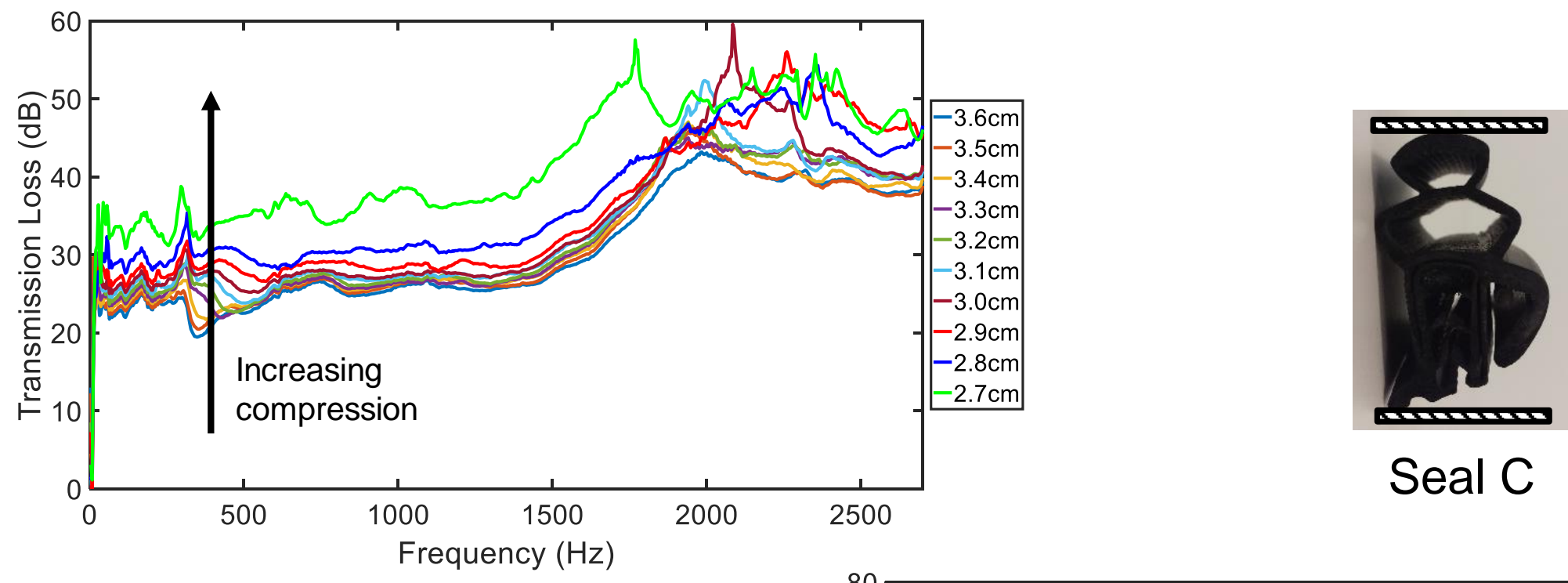

- Shift of TL peak to lower frequencies as compression increases

- $\mathrm{TL}$ is similar at low compression but increases at high compression

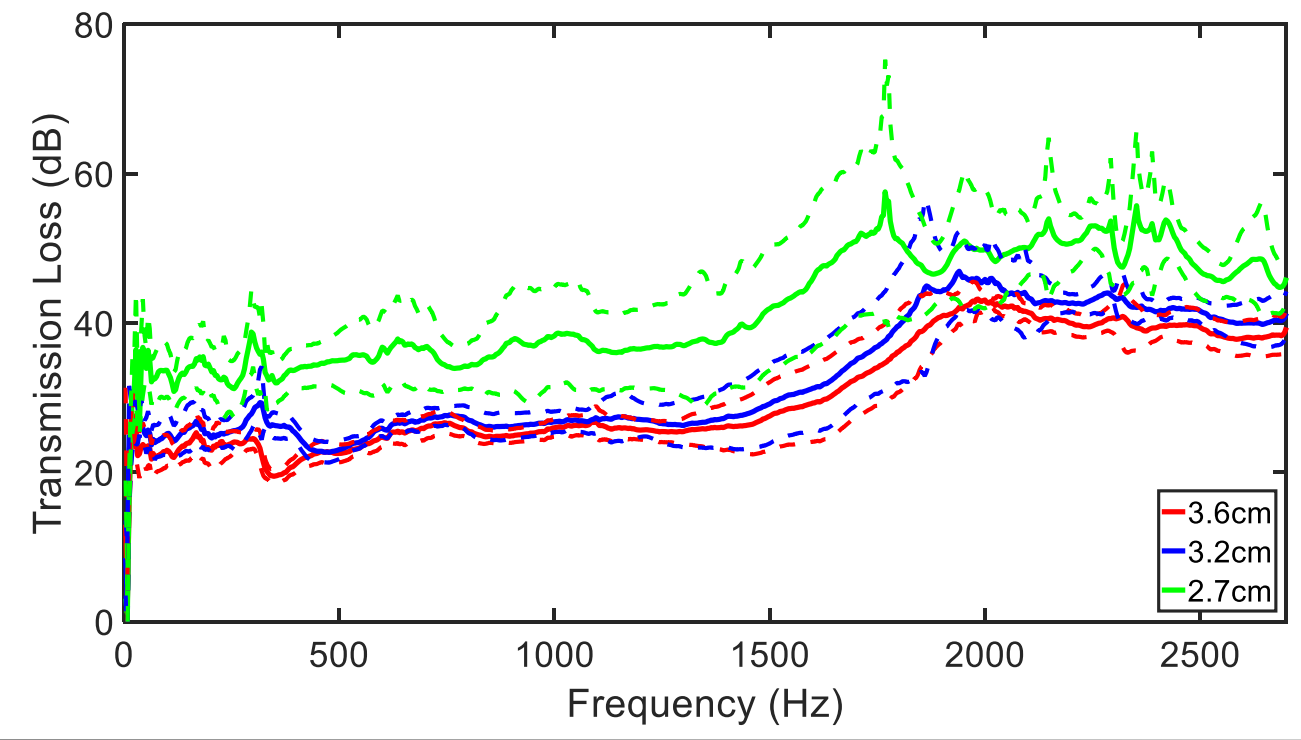




\section{Corrected average transmission loss for seal D with standard}

deviations from 10 trials at each compression
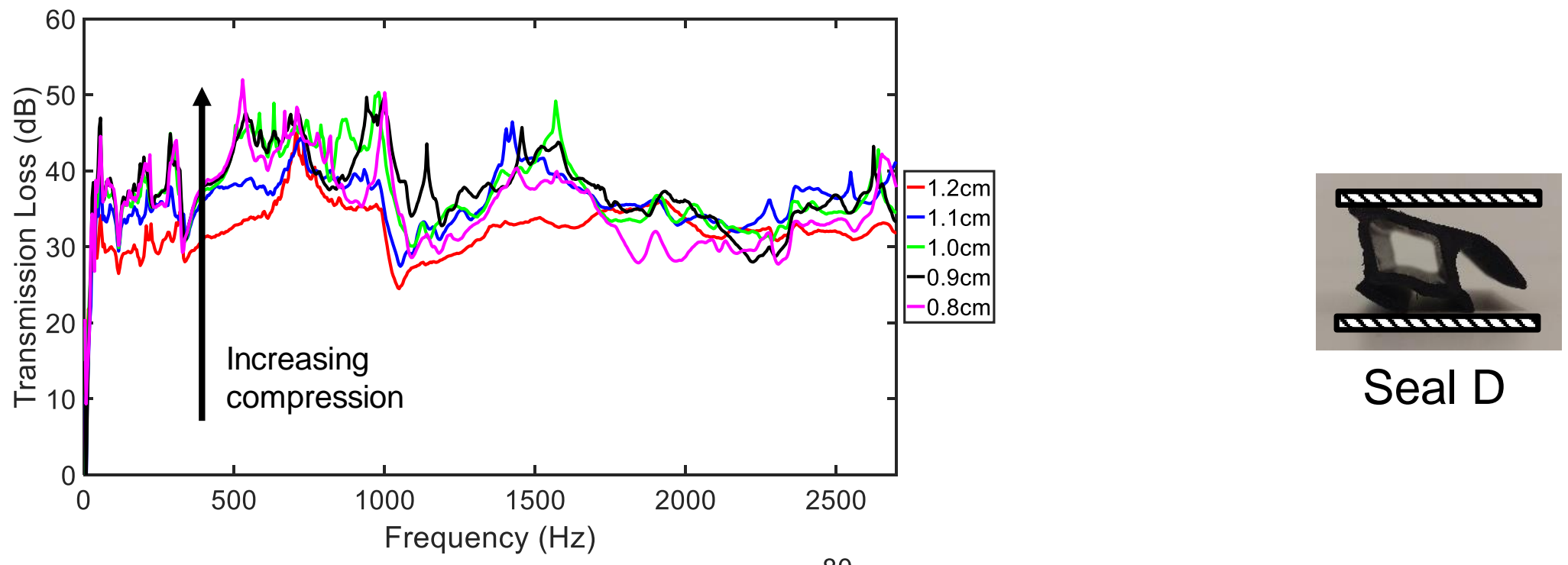

- Relatively large scatter for this case

- Effect of compression is small due to limited compression capability

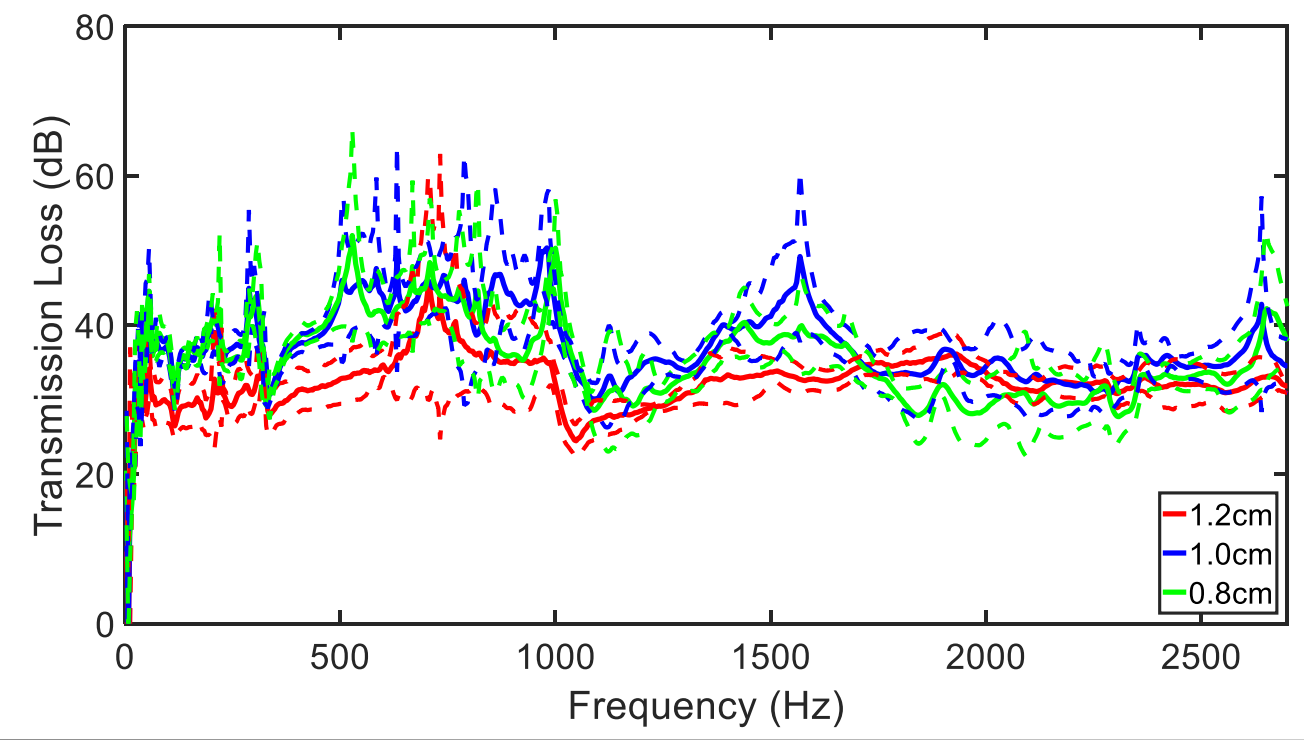


Corrected average transmission loss for seal E with standard deviations from 10 trials at each compression
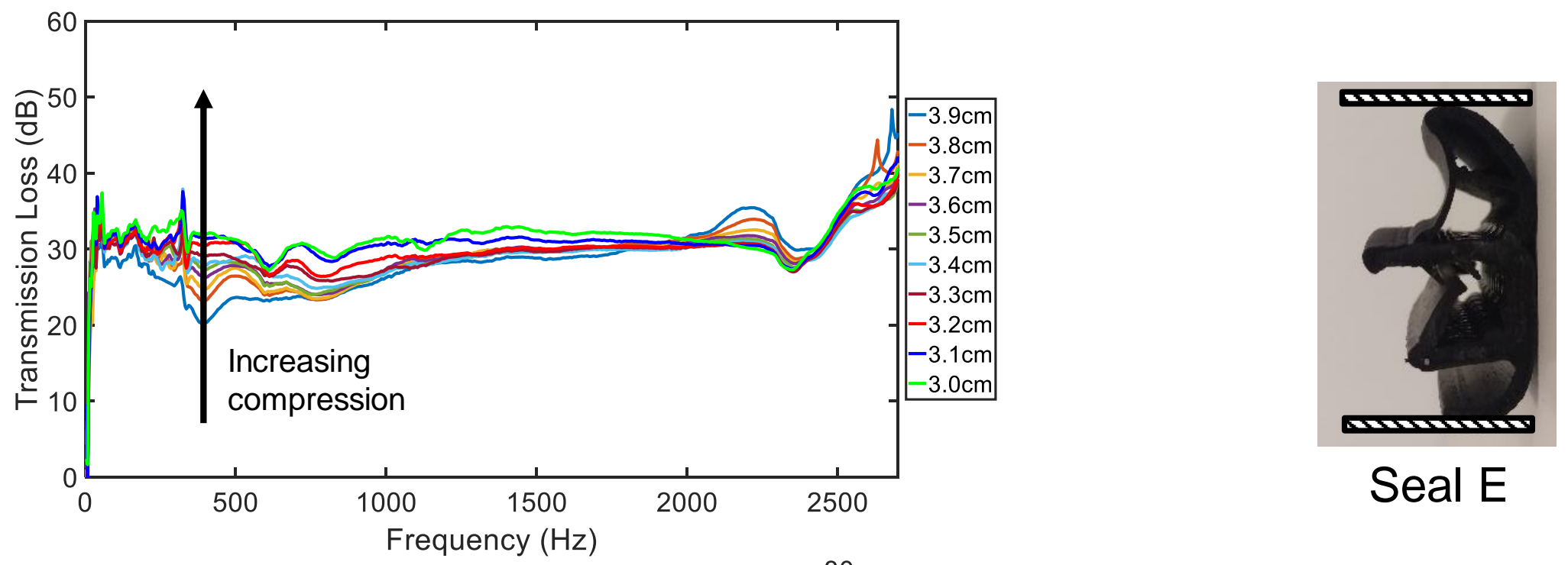

- Very consistent results

- Effect of compression is very small

- TL almost independent of compression

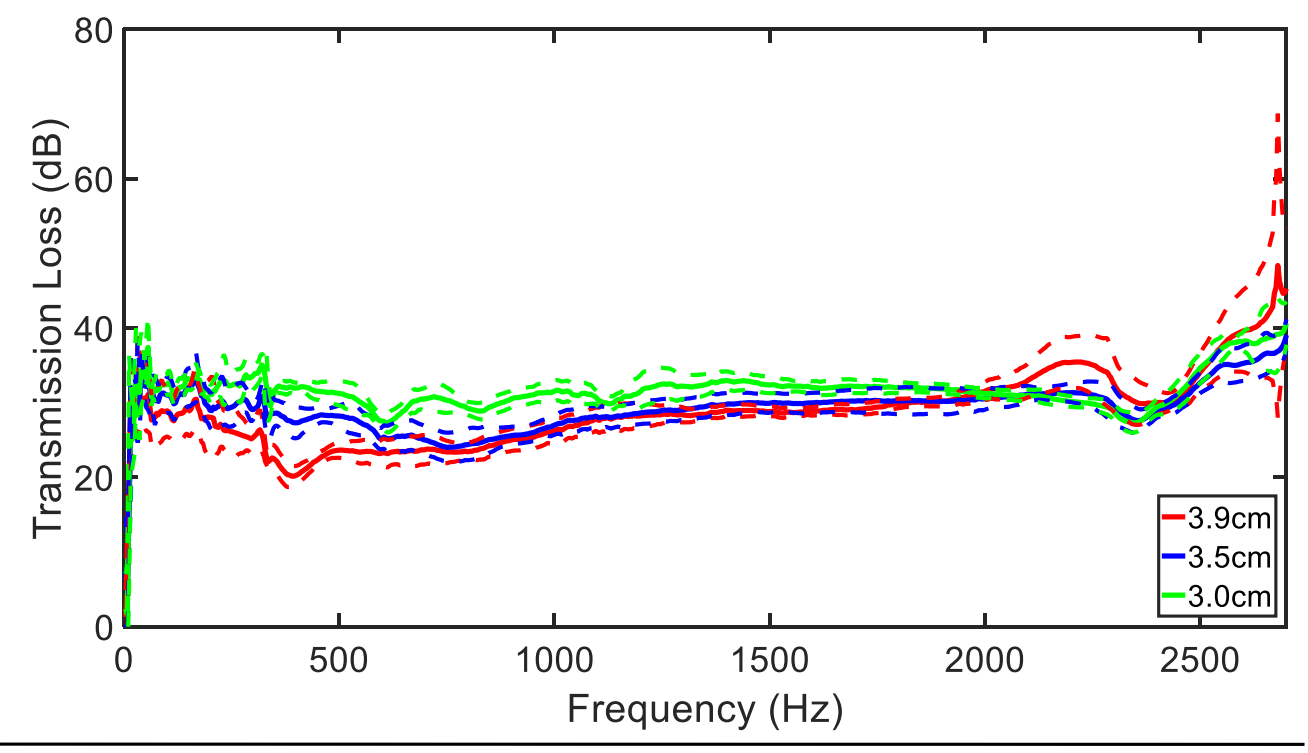




\section{Conclusions}

A desktop procedure for measuring the acoustic properties of automotive door sealing systems was described.

- The procedure described could replace the previously conventional method that made use of reverberation chambers.

- It was observed that the transmission loss of the seals progressively increased with increasing compression and the stiffening effect of compression caused some features to shift to lower frequencies.

- A modified clamp system that more accurately represents the way the seals are held in practice should be the next step of the research to increase the utility of this procedure.

- Better to use "reference" materials having TL's closer to samples.

\section{Acknowledgements}

- Our thanks to Ford Motor Company, and in particular, John Nalevanko, for supporting this research, to Caleb Wagner for designing and fabricating the sample holder, and to the 3M Company for providing the square-section standing wave tube. 


\section{References}

Robert J. Danforth III and Luc Mongeau, "Sound transmission through road vehicle primary bulb seal assemblies," Herrick Labs report HL 96-14 Report \#3086-2, December 1996.

Junhong Park and Luc Mongeau, "Effects of mechanical properties of sealing systems on aerodynamic noise generation inside vehicles," Herrick Labs report $H L$ 2002-1, May 2002.

Julio A. Cordioli, Márcio Calçada, Teo Rocha, Vincent Cotoni, and Phil Shorter, "Application of the Hybrid FE-SEA Method to Predict Sound Transmission Through Complex Sealing Systems," SAE International 2011-01-1708, May 2011.

Bryan H. Song and J. Stuart Bolton, "A transfer-matrix approach for estimating the characteristic impedance and wave numbers of limp and rigid porous materials," Journal of the Acoustical Society of America, Vol. 107, 1131-1152, 2000.

J. Stuart Bolton, Taewook Yoo, and Oliviero Olivieri, "Measurement of Normal Incidence Transmission Loss and Other Acoustical Properties of Materials Placed in a Standing Wave Tube," Bruel \& Kjær Technical Review No.1, 2007.

ASTM International, "Standard Test Method for Measurement of Normal Incidence Sound Transmission of Acoustical Materials Based on the Transfer Matrix Method," ASTM International E2611, 2009. 